\title{
Consent and Political Legitimacy
}

\begin{abstract}
Consent plays a leading role in many theories of political legitimacy. Two approaches to theorizing about why consent matters for legitimacy have been dominant: the hypothetical consent approach, which argues that a regime is legitimate insofar as all of its subjects would agree to it under idealized conditions, and the express consent approach, which argues that a regime is legitimate for each subject insofar as that subject has expressly consented to it. In this paper, I argue that both views involve unacceptable idealizations. Instead, I develop and defend a new conception of political legitimacy based on actual consent. According to this view, a state is legitimate insofar as it achieves actual quality consent to rule. Quality consent obtains when a subject consents to her state on the basis of a judgment of governance success, provided that the judgment does not conflict with the government's minimal aim, i.e. basic security for all subjects. The view that I develop, therefore, values consent to rule in a novel way, permitting it to count in favor of legitimacy even when it is not unanimous. Accordingly, a state comes to be legitimate by governing in such a way as to be widely recognized as doing so successfully by its subjects.
\end{abstract}

\section{Introduction}

Political legitimacy rests on the consent of the governed. ${ }^{1}$ Many theories of legitimacy accept this basic principle in some form, but they differ on how consent is to be understood.

Today, those who believe that consent matters for legitimacy typically articulate its significance via theoretical idealizations. Those idealizations have costs. I will argue that we need not incur those costs, and indeed we ought not incur them, in a consent-based theory of legitimacy. Ultimately, I will defend an alternative view that avoids those costs and has considerable

\footnotetext{
${ }^{1}$ For helpful comments on earlier drafts, I would like to thank Samuel Asarnow, Mark Budolfson, Lee-Ann Chae, Alan Code, Joshua Cohen, Brian Coyne, Bryan Cwik, Jorah Dannenberg, David Estlund, Blake Francis, David Hills, John Horton, Jeff Howard, Abby Everett Jacques, Dhananjay Jagannathan, Richard Kraut, Cristina LaFont, RJ Leland, Nethanel Lipshitz, Benjamin Miller, Katherine Meadows, Jane Mansbridge, Martha Nussbaum, Josiah Ober, Debra Satz, Kevin Vallier, Han van Wietmarschen, Allen Wood, and anonymous referees. I am also grateful for comments from audiences at Stanford University, University of Chicago, Northwestern University, and the 2014 Oxford Studies in Political Philosophy Workshop. I wish to acknowledge the generous support of the Stanford Humanities Center, the Institute for Humane Studies, and the University of Chicago Law School.
} 
advantages. While I cannot defend a comprehensive account of political legitimacy here, I hope to say enough to motivate an approach to legitimacy that is, I believe, superior to the dominant approaches in political philosophy.

The views I criticize fall into two camps. Those in the contractualist family believe legitimacy rests on hypothetical consent, where this consent is imputed based on certain presumptions about the agent's evaluative stance. However, these presumptions fail to adequately respect the subject's interest in voluntary rule, since legitimacy does not depend on whether subjects actually consent. On the other hand, those in the voluntarist family believe legitimacy rests on actual consent, but an individual's consent renders the government legitimate only for that individual. However, since the unanimous consent of all subjects is unattainable, these views must idealize about the degree of unanimity required to achieve legitimacy overall, or else accept that no past or present regimes are legitimate. The shortcomings of both views seem to create an impasse. Neither side can see an alternative consent-based theory that avoids these costs. I will argue for a new view that does so, while retaining much that is of value in the other views. A discussion of these shortcomings will occupy the first portion of the paper. In the second part of the paper, I present the new view and show why it has significant advantages as a theory of political legitimacy.

In order to explain the shortcomings of current consent views of legitimacy, I want to begin with some general thoughts about how the question of legitimacy is to be theorized. One basic question concerns the objects of our assessments of legitimacy. I take the paradigmatic object of legitimacy assessments to be political orders broadly construed, which I will call regimes. ${ }^{2}$ For purposes of this paper, I take legitimacy assessments to be addressing the question

\footnotetext{
${ }^{2}$ Assessments of regimes may include abstract institutional features (e.g. constitutional essentials) as well as concrete instantiations of those features (e.g. how the ruling party or government is currently exercising power via
} 
of when a regime has appropriate standing to exercise power over its subjects. ${ }^{3}$ It is also possible to assess the legitimacy of ruling parties, policies, laws, and even particular actions, but I will be concerned in this paper with the overall political or constitutional order.

Second, I observe that many theorists subscribe to a strict distinction between normative and descriptive legitimacy. ${ }^{4}$ I think this dichotomy is too strong. Theorists ought to give more consideration to how the term is used in non-philosophical discourse, where it is more or less used in the sociological sense first identified by Max Weber. ${ }^{5}$ In these discourses, broadly speaking, legitimacy is a social fact about whether the subjects of a regime believe it has authority. In my view, it is worthwhile to explore what normative significance this sociological concept may have. Relatedly, I observe that theorists who are focused on a theory of normative legitimacy often build in liberal and democratic presumptions. For example, one family of views claims that a regime is illegitimate unless it treats all subjects as free and equal. ${ }^{6}$ While such a demanding stance might license us to call illiberal or undemocratic regimes illegitimate, it also runs together several distinct registers of political evaluation. In what follows, I aim to show how it is possible and fruitful to keep the assessment of legitimacy distinct from other modes of political evaluation, such as democracy and liberalism.

Finally, I observe that some theorists advance views of legitimacy that are quite demanding. If the theories were applied as stated, the result would be that no regime in the past

\footnotetext{
those institutional features).

${ }^{3}$ Because part of my aim is to propose a new account of the relationship between consent and legitimacy, leading off the inquiry with a more explicit definition would be either question-begging or self-defeating. For example, "right to rule" approaches tend to result in accounts of justified coercion (which often cast consent in a contractualist role) or justified authority (which often sideline consent altogether).

4 (Buchanan and Keohane 2006), (Copp 1999), (Rawls 2001).

${ }^{5}$ For a succinct discussion of the contemporary practice of making legitimacy assessments, see Chapter 5 of (Buchanan 2013). For Weber's original discussion, see (Weber 1978).

${ }^{6}$ Examples abound, but the seminal statement is Rawls's liberal principle of legitimacy: "Our exercise of political power is fully proper only when it is exercised in accordance with a constitution the essentials of which all citizens as free and equal may reasonably be expected to endorse in the light of principles and ideals acceptable to their common human reason" (Rawls, 1996, 137\}.
} 
or in the present would meet the standards of legitimacy. This approach to theorizing legitimacy has limited usefulness, in my view, and it also invites a kind of resignation on the part of political actors. Ultimately, I will argue that the alternative conception of legitimacy defended in the paper does better than other consent-based theories at fulfilling three separate desiderata: articulating a useful conception of legitimacy, showing how it is distinct from other modes of political evaluation, and explaining why it is valuable.

\section{Shortcomings of Other Consent Theories}

The two families of consent based theories of legitimacy that I will discuss may be formulated as follows:

Voluntarism: A regime is legitimate for each subject insofar as that subject has actually consented to it. Contractualism: A regime is legitimate insofar as every subject would consent under idealized conditions.

To motivate the development of an alternative, I will outline some shortcomings in these versions of consent theory. First I will address contractualism, to which I devote more space because it is by far the predominant philosophical approach to legitimacy.

Contractualism employs the idea of a hypothetical contract or unforced agreement among free and equal persons. ${ }^{7}$ The contractualist claims, very roughly, that a regime gains legitimacy by organizing institutions around principles of justification that all citizens would freely accept under certain conditions. The construction of the hypothetical choice situation employs a variety of idealizing assumptions, typically including citizens' willingness to cooperate on fair terms, the reasonableness of citizens' value judgments, the common interest in membership in a group on

\footnotetext{
${ }^{7}$ While accounts of political community are more often called contractarian (based on claims of mutual advantage), I deliberately employ the term contractualist in order to consider just those theories that are based on the "equal moral status of persons," drawing on their "capacity for rational autonomous agency." See (Ashford and Mulgan 2012).
} 
terms of equal standing, etc. In order to isolate the consent element of the view, I will focus on the formal feature of hypothetical acceptability. ${ }^{8}$ The relevant aspect of the contractualist position, then, is the idea that regimes are legitimate (at least in part) because their justification is hypothetically acceptable to all citizens. ${ }^{9}$ I will now discuss two shortcomings of contractualism as a theory of legitimacy: the problem of involuntary rule, which arises at both the collective and individual level, and the challenge of partisan evaluation.

\subsection{The Costs of Contractualism: Collective Involuntary Rule}

First, contractualism faces a difficulty in explaining some basic intuitions we have about voluntary and involuntary rule. Consider the tendency we have to associate popular acceptance with legitimacy or to associate popular rejection with a lack of legitimacy. We seem to think there is something problematic or amiss when the subjects en masse disavow the regime that claims authority over them. We might even say that the subjects, at a collective level, are involuntarily subjected to rule in some sense. To make this point vivid, consider the following illustration: imagine there are two political communities that have a similar constitution and government, but in one case $80 \%$ of the subjects affirm the regime, and in the other case, $30 \%$ affirm the regime. (Assume that both regimes are justified by publicly acceptable reasons.) It seems natural and intuitive to say that a regime garnering the support of $30 \%$ of its subjects is less legitimate than one garnering $80 \%$ support. How might this intuition be explained?

\footnotetext{
${ }^{8}$ Contractualists may reply that justification is not conferred by consent per se, but rather that idealized agreement is used to model moral reasoning - and especially to identify the morally relevant features of a relationship. So understood, contractualism ought not be taken as a consent-based theory. But if the model at all relies for its validity on the idea of unforced agreement (and, consequently, its value in realizing a certain kind of respect), then it draws on some ideal of voluntary acceptance of rule. Contractualists might deny that the notion of hypothetical acceptability exhausts their defense of legitimacy, but I think they must admit that it comprises their account of the role consent plays in legitimacy.

${ }^{9}$ Of the theorists who think hypothetical acceptability is necessary for legitimacy, some also think it is sufficient, or that it is sufficient in combination with other factors related to hypothetical acceptability. See (Cohen 1996) and
} 
Perhaps one explanation is that the $80 \%$ support is evidence that some of the government's policies have superior welfare outcomes (either aggregatively or distributively). But now, stipulate that both have the same welfare outcomes: if one regime garners $80 \%$ support while the other only $30 \%$, it seems there is still something problematic or amiss about the regime that lacks popular support. One might also argue in this vein that $80 \%$ support is evidence of the epistemic superiority of the governance - that is, those in power know more and thus govern better (even if, by luck, the outcomes are on a par). Then, one might argue, the difference in degree of popular support accurately reflects the difference in likelihood that the regime is governed knowledgeably. Does the intuition remain? In response I would make a similar stipulation: suppose that the governments of the two countries exhibit identical epistemic virtues and are equally likely to govern knowledgeably, but one garners $80 \%$ support while the other garners $30 \%$. Does the intuition remain? Consider again the non-supporting portions of the population: in the $30 \%$ case, a large majority of the population $(70 \%)$ is involuntarily subject to a government they do not support - though it may be due to their lacking the cognitive or epistemic capacities to see that it is worthy of their support. In the $80 \%$ case, this subjection is true of only a small minority of the population $(20 \%)$.

One might still argue that intuitions about the 30/80 illustration reflect our concerns about the stability of the polity. Though somewhat plausible, a reference to stability still does not fully explain the intuition, since stipulating a parity of stability-related consequences nonetheless leaves us with a residual discomfort. When a group of subjects does not accept their regime, this situation is to be regretted and avoided if possible, and at the very least it ought to be minimized. In general, most of us have an aversion to having a government or regime deliberately forced upon us, and we infer that others are similarly averse to this treatment. The 30/80 illustration 
alerts us to a concern about involuntary subjection to a political order, no matter the merits of that order.

Theorists of legitimacy, including contractualists, must either deny that the problem of collective involuntary rule has intuitive force, deny that its force has relevance for legitimacy, or account for it in some way. In my view, the problem ought not to be denied, because it raises a moral concern about involuntary subjection to a political order, even if the order is worthy of support. Nevertheless, a contractualist may accept the intuition that something has gone wrong, but still question its relevance for legitimacy. But this denial is strained. If legitimacy is understood, in the broadest terms, as appropriate rule, then widespread popular rejection of such rule seems directly relevant. Contractualism, however, is ill-equipped for accommodating the way in which actual popular acceptance and rejection matter, because it locates all the facts relevant for legitimacy within the hypothetical choice situation.

According to the contractualist, legitimacy arises from the unanimous consent of parties who are idealized in certain kinds of ways: if a person's deliberation were to meet certain stipulated conditions, then she would consent to a political order with certain features. Thus the stipulations contained in the hypothetical choice situation are paramount in determining when and how consent bears on legitimacy. The stipulations mediate, structure, and constrain the way consent can alter legitimacy assessments.

The difficulty with forcing consent's significance to be mediated by hypothetical idealizations is that we begin to attenuate the moral force of consent, or rather, the moral force of non-consent. In The Social Contract, Rousseau insists that once the people are acknowledged as being sovereign, their scope of authority cannot be limited, not even by the hypothetical contract itself. Popular sovereignty requires periodic referenda by the people on the form of government, 
in which is it possible to change the regime entirely. He says, "In the state there is no fundamental law that cannot be revoked, not even the social compact. For if all the citizens were to assemble in order to break this compact by common agreement, no one could doubt that it was legitimately broken" (Rousseau 1987, III.xviii). According to Rousseau, any regime relying on agreement for its legitimacy is thereby liable to lose its legitimacy if the agreement is revoked. Essentially, the people's actual exercise of free choice cannot be constrained by its hypothetical exercise of free choice.

While Rousseau did not fully spell out the implications of these claims about revoking the social compact, his analysis underscores a tension in the hypothetical consent approach to legitimacy. Within the framework of contractualism, we lack a principled way to integrate the hypothetical consent of the governed and the actual consent of the governed, though they both seem to matter for legitimacy. If the contractualist approach does not accommodate a direct sensitivity to actual consent to rule on the part of the subjects, then it is hard to see how it can address the concern about involuntary rule at the collective level.

\subsection{The Costs of Contractualism: Individual Involuntary Rule}

Contractualist theories of legitimacy face another problem related to the idea of voluntary rule - this time, the problem is visible at the level of the individual. Consider the following stylized dialogue between the spokesman for a regime (say, a government official) and a subject. If the official justified an exercise of authority by claiming that the subjects willed it in a hypothetical sense, then if a subject wished to object, his objection would have the following form: "No, I did not will it in a hypothetical sense, and here is why." With the dispute having been framed in such a way, the official and the subject would begin arguing about whether the 
exercise of authority meets certain conditions, namely those conditions that would settle whether he willed it in a hypothetical sense. If the official's reasoning prevails, then she will have simultaneously settled both whether the justification is valid (i.e. whether the specified conditions were met) and whether it possesses the relevant sort of recognition by subjects.

For a contractualist, it does not matter for legitimacy whether an individual does recognize (or consent to) rule, as long as he would recognize (or consent to) rule. In other words, the withholding of recognition of a regime cannot bear directly on legitimacy, because the normative space required in order for the individual's withholding to matter for legitimacy (i.e. to alter legitimacy assessments) is eliminated whenever the regime's own claim to be contractually justified is true. While some may see this feature of contractualism as its strength, there is nevertheless something morally troubling when an individual is treated as though her actual nonconsent does not matter for legitimacy, as long as her hypothetical consent has been obtained (i.e. established through philosophical argument). There are multiple domains in which such treatment would be obviously troubling. For example, according to 'informed consent' requirements in medicine, actual non-consent settles the matter even when there are very good justifications for consent. This sort of moral unease gives us good reason to separate the validity of a regime's claims from the recognition of a regime's claims, such that we can identify situations in which one has been achieved without the other.

Preserving the independent significance of recognition requires that when a subject fails to recognize something even when it is fully warranted, this recognitional failure matters. When the lack of recognition matters independently of whether it is warranted, then when recognition is correct and freely given, it adds something beyond hypothetical recognition: it pays due respect to the individual's standing as recognizer. A contractualist defense of political legitimacy 
inadequately respects individuals' standing as independent recognizers of claims that are made in the justification of rule. A devoted contractualist may still ask: why is this a problem? It's a problem because it doesn't sufficiently respect an individual's capacity to evaluate rule in their non-idealized state. The contractualist might respond that it respects their evaluative capacities in a different, more generic way. The further reply is that while this generic kind of respect has value, legitimacy should be about actual attitudes, because the attainment of voluntary rule should be sensitive to particularity at the individual level.

In a related line of criticism, A. John Simmons argues that contractualism collapses the distinction between justification to a hypothetical citizen and justification to a particular citizen. He points out that legitimacy depends on historical facts about the relationship between an individual and an institution, a dimension that is missed on the Kantian approach:

The proper grounds for claims of legitimacy concern the transactional components of the specific relationship between individual and institution... No specific actual history of morally significant relations between a particular state and each of its subjects is thought by Kant to be necessary to support the transition from justifying the state to legitimating a particular state with respect to all of its subjects... Therefore, Kantians have appropriated the justificatory force of voluntarism without having any respect for people's actual choices. (Simmons 1999, 755-756) $)^{10}$

Here Simmons emphasizes the way in which the historical facts about a state's relationship with an individual are relevant to its legitimacy. ${ }^{11}$ The notion of 'standing-to-recognize,' reflects our appropriate concern with the particularity of the relationship between regimes and individual subjects.

\subsection{The Costs of Contractualism: Partisan Legitimacy}

\footnotetext{
${ }^{10}$ As a matter of technical clarification, Simmons' terminology differs from mine. He says justification pertains to whether a state has a right to exist, while legitimacy pertains to the "complex moral right [a particular state] possesses to be the exclusive imposer of binding duties on its subjects, to have its subjects comply with these duties, and to use coercion to enforce these duties." Simmons also equates legitimacy with the individual obligation to obey, a "logical correlate" I do not accept (Simmons 1999, 746).
} 
I have argued that contractualism incurs theoretical costs in its inability to register the withholding of voluntary acceptance of rule, both at the collective and the individual level. I emphasized that this inability is a failure to give due respect to the actual judgments of individuals and communities in their real circumstances (as opposed to idealized circumstances), and I suggested that this failure weakens the claim that legitimacy corresponds to the attainment of voluntary rule. Now I want to propose that the contractualist's need to idealize consent has a further problematic dimension. The contractualist prejudges which categories of political facts are relevant for consent, thereby making legitimacy unnecessarily partisan. Some evidence of this partisan mode is the tendency for contractualist formulations of legitimacy to involve liberal and democratic presuppositions as a matter of definition. These presuppositions in turn make it impossible for non-democratic and non-liberal forms of government to achieve legitimacy. Note that the putative illegitimacy of these regimes does not follow from any separate considerations but rather from the role of consent in establishing legitimacy. This is a theoretical entanglement we would do well to avoid.

The contractualist approach I have described consists of two distinct claims: we each deserve acceptable justification for claims of authority being made on us, and the provision of such justification is necessary and sufficient for establishing legitimacy (understood as the consent of the governed). The contractualist must commit to some conditions being necessary and sufficient for imputing universal agreement, howsoever the hypothetical choice is constructed. Thus, contractualism determines ex ante, and on behalf of everyone, which moral considerations do and do not matter for legitimacy, and how they are to be assessed. By determining in advance which moral considerations do and don't matter for establishing

\footnotetext{
${ }^{11}$ For a fuller discussion of the way in which our conception of legitimacy ought to accommodate the fact that it is evaluated differently in different historical circumstances, see (Horton 2012).
} 
hypothetical consent, contractualist views draw a line around the acceptable grounds for the consent of the governed in terms of a particular characterization of the moral justification of government. Contractualism must, therefore, rely on a 'partisan' view of how consent fixes the facts about legitimacy.

In many cases, the moral considerations that are adverted to by contractualists concern whether subjects are treated as free and equal, in some sense, by their government. This common formulation embeds liberal and democratic requirements into the ideal of voluntary rule, the very ideal underlying consent-based theories of legitimacy — indeed, the securing of unanimous consent is itself an expression of free and equal treatment. Contractualists may object that what I identify as a theoretical cost of their approach is precisely the feature they consider to be its theoretical strength. But I think they have not taken a wide enough view about the costs that are incurred. Advocating such a partisan view prevents us from having a theory of legitimacy that applies, without significant idealization, to the situations in which we find ourselves today. For instance, it seems plausible that there could be regimes that are legitimate but not democratic; conversely, there could be regimes that are democratic but not legitimate. It would be useful to have a conception of legitimacy that can help us understand why things like liberal rights, equality, and democracy contribute to the attainment of legitimacy (if they do), without building those political ideals into our very concept of legitimacy. In what follows, I present an alternative conception of political legitimacy that can be usefully applied to non-liberal and non-democratic states, thereby avoiding a partisan articulation of the role of consent in establishing legitimacy.

\subsection{The Costs of Voluntarism}

I turn now to a discussion of the shortcomings of voluntarism. According to the 
voluntarist variant of consent theory, a regime is legitimate insofar as each subject actually consents to it. This consent then is binding in two ways: the state is bound to exercise authority within the limits of the expressed consent, and the individual is bound to obey the authority to which he has consented. A recent advocate of the view, A. John Simmons, argues that the legitimacy of the state arises only from the consent of the individual (Simmons 1999). On this view, the actual consent of the individual is necessary and (usually) sufficient for the state to possess legitimacy with respect to that citizen. ${ }^{12}$ The picture often relies on a notion of natural rights as pre-political moral entitlements, such that each person has a right to defend their entitlements against encroachments by others. The state's authority arises from the deliberate transfer of this right to a single authority, who makes determinations and exercises coercion in order to enforce each individual's rights. This view construes legitimacy as a property of the relationship between the state and an individual, meaning that the state can be legitimate with respect to one citizen and illegitimate with respect to another. I designate this view a form of voluntarism because it so closely tailors legitimacy assessments to facts about the will of the individual.

There are several problems with this view, but a major concern is that the required consent standard cannot be met in a way that issues in legitimacy. One sense in which it cannot be met is that it is impossible to get the consent of every single individual subject. If unanimity is impossible, one might be forced to conclude that legitimacy is virtually unattainable. Indeed, Simmons bites the bullet and concludes that "no existing states are legitimate."13 This problem arises because voluntarism is sensitive to the moral significance of consent, but it is sensitive in

\footnotetext{
${ }^{12}$ Simmons adds a proviso to whether consent is sufficient (derived from Locke): "We cannot bind ourselves by consent to immoral arrangements" (Simmons 1999, 746). I return to this proviso later.

${ }^{13}$ He says, "Because I subscribe to political voluntarism as the correct account of these transactional grounds for legitimacy, and because I believe no actual states satisfy the requirements of this voluntarism, I also believe that no
} 
such a way as to make unanimous consent necessary for legitimacy. Alternatively, one might say that unanimous consent is not necessary for legitimacy overall, but only necessary for legitimacy construed as a feature distributed across individuals. The problem would then be that legitimacy is piecemeal, not a feature of a regime overall. When we ask whether a regime is legitimate, we are concerned with its general standing with respect to the subjects of the regime. It is not clear how piecemeal legitimacy could address the question of general standing without abstracting away, through idealization, from some subjects' non-consent, thereby treating them differently than the consenting subjects.

And finally, the voluntarist implicitly relies on an implausible connection between consent and an ideal of self-rule. ${ }^{14}$ The voluntarist seeks to derive legitimacy by construing consent as a kind of delegation of authority that preserves an ideal of self-rule. The individual avoids a pernicious subjection to the rule of others because their obligation to obey arises only by their own consent. In positing such a direct connection between consent and the avoidance of involuntary subjection, the voluntarist implicitly presumes that consent evinces some status approximating self-rule. But it is very difficult to see how granting consent to one's regime ought to count as self-rule without idealizing to a significant degree. ${ }^{15}$ Even in societies whose government is highly participatory, construing a subject's consent as evincing self-rule requires making highly controversial assumptions about collective will formation. The voluntarist strategy of deriving legitimacy from the willing transfer by individuals of those rights and privileges associated with self-rule is not a realistic model for today's political orders. Therefore the voluntarist must either stretch the definition of consent so far that it is imputed on the basis of

existing states are legitimate." However, Simmons goes on to argue that he thinks states that are neither justified nor legitimate can nevertheless act in ways that are justified (e.g. to prevent violent crime) (Simmons 1999, 269-770).

${ }^{14}$ This problem is most evident in libertarian approaches to legitimacy based on the idea of self-ownership. For the seminal statement, see (Nozick 1974). For a more contemporary version, see (Huemer 2012). 
factors whose connection to self-rule is highly attenuated and idealized, or he must admit that the required consent standard cannot be met in a way that is sufficient for legitimacy.

\section{An Alternative Conception of Legitimacy}

In the remaining discussion, I defend an alternative view of legitimacy, arguing that it is superior to other consent based views of legitimacy. A basic statement of the view, which I call the sovereignty conception, is that a regime is legitimate insofar as it achieves actual quality consent to rule based on positive governance assessments. The view retains a key insight of voluntarism: actual consent matters. But, since unanimous consent is impossible, the sovereignty conception focuses on achieving actual consent among a high proportion of subjects. At the same time, the sovereignty view retains a key insight of contractualism: not all actual consent matters. The sovereignty conception employs the notion of quality consent because consent's significance is dependent on meeting certain minimal conditions -- namely, being based on an individual's positive governance assessment. The sovereignty conception, therefore, stakes out an innovative position in theorizing about how consent relates to legitimacy: a regime is legitimate insofar as it achieves consent that is (a) actual rather than idealized, (b) proportional rather than unanimous, and (c) based on positive governance assessments. In order to show how this view is superior to other views, I first need to explain these interrelated aspects of the sovereignty view. The next three sections lay out the key elements of the view.

\subsection{Voluntary Rule}

I will introduce the sovereignty conception by returning to the original ideal underlying

\footnotetext{
${ }^{15}$ For a recent exposition of this problem from the perspective of the neorepublican tradition, see Chapter 3 of (Pettit
} 
consent theories of legitimacy: the ideal of voluntary rule ${ }^{16}$ It is plausible to think that each individual, considered in his role as the subject of a political order, has an interest in being ruled voluntarily. One is ruled voluntarily when one is willing to remain a subject of one's particular political order, all things considered. One may characterize a willing subject as one who freely consents to the particular system of rule to which one is subject. An unwilling subject is one who disavows being ruled to such a degree that one is willing to engage in disruptive and costly resistance (if it stands a chance of being effective) in order to fundamentally change the constitutional order, including the basic power-conferring norms of that order ${ }^{17}$ It also seems plausible to think that this interest in voluntary rule is significant and universal, meaning that it is important for everyone, though it need not override all other interests at stake in politics.

However, being a willing subject of a regime is not unconditionally good. Not every voluntary act of an individual has import simply because it is freely chosen - conditions must be met. Accordingly, consent-to-rule is only valuable when it meets certain conditions. I will say more about these conditions shortly, but what is important to note here is that consent's role in realizing the interest in voluntary rule is going to be conditional. This conditionality illustrates consent's nature as a dependent good, a good whose value depends on other things. I will call instances of consent that meet the relevant conditions 'quality consent. ${ }^{18}$

Although the significance of consent is conditional, its value is nevertheless noninstrumental. How should we understand this kind of good, something that has dependent non-

\footnotetext{
2012).

${ }^{16}$ Since I think voluntary rule is something that all consent theorists would accept at some level of generality, I take myself to be elaborating a particular interpretation of voluntary rule.

${ }^{17}$ I cannot give a full definition here, but determining whether any given person is a willing subject will need to include reference to both attitudes and behavioral dispositions. The paradigmatic case of an unwilling subject is the revolutionary.

${ }^{18}$ I acknowledge that some readers may be inclined to focus on validity when thinking about consent, but I focus on its value, i.e. why we should care whether there is consent, since this account will need to underlie any account of its validity.
} 
instrumental value? Joseph Raz elucidates the structure of a dependent, non-instrumental good when he discusses the concept of autonomy:

There is no contradiction in claiming both that autonomy is intrinsically valuable and that the fact that people's lives are autonomous contributes to their well-being only to the extent that they engage in worthwhile pursuits. What is intrinsically valuable can be, and in the case of autonomy is, valuable as a constituent of a good in itself. Remove other elements of the good in itself and it may turn worthless, or even bad. (Raz 1988, 1228-9)

For Raz, autonomous choice has intrinsic but dependent value: when what is chosen is valuable (e.g. a musical project), the fact that it is autonomously chosen contributes intrinsically to its value in an organic way. ${ }^{19}$ But if the object of choice is not valuable (e.g. an assassination project), then something that would otherwise be of value has no value. ${ }^{20}$ In sum, the value of autonomy cannot be made instrumental to the value of what is chosen, though its value depends on what is chosen. In my view, consent-to-be-ruled is analogous to Raz's claim about autonomy in that its value may be nullified if certain conditions are not met, but when present it has a noninstrumental value that cannot be reduced to the conditions on which its value depends.

\subsection{Quality Consent}

The sovereignty conception claims that a regime is legitimate insofar as it achieves stable and widespread actual quality consent to rule among subjects. I construe quality consent as consent based on positive governance assessments. At a minimum, a positive governance assessment is the judgment by a particular subject of some sort of governance success. The most basic claim of government is to benefit its subjects through the exercise of power, so the relevant

\footnotetext{
${ }^{19}$ I wish to avoid claims of intrinsic value, so I claim that it has "non-instrumental" value. For an extensive discussion of dependent non-instrumental value, see (Sandbu 2007).

${ }^{20}$ It is important not to confuse Raz's point with one that sounds similar, articulated by Amartya Sen among others, about the role of agency in making something valuable. (Sen 1997) distinguishes between comprehensive outcomes and culmination outcomes, where the former are valued for some aspect of how they are achieved, e.g. involving agency. Raz is concerned with how the value of autonomous choice depends on the value of what is chosen, while Sen's concern is with how the value of what is chosen depends on whether agency is involved.
} 
recognition of success is a subject's judgment regarding whether benefits have arisen from the exercise of power. I call these sorts of judgments governance assessments, and they are in terms of subjective welfare, i.e. perceived welfare at either the individual or collective level. On the basis of what a subject considers relevant and valuable by her own lights, she forms an overall subjective assessment of governance and, on that basis, consents to her political order. The view is deliberately permissive about what counts as a positive governance assessment.

Therefore, on the sovereignty conception, a regime comes to be legitimate by delivering benefits through the exercise of power in such a way as to be widely recognized as doing so by its subjects. In this scenario, the rulers seek and promote the common good as they see it, and the subjects voluntarily accept their subjection because they think the rulers are advancing the common good, as each subject sees it. This expansive notion of a positive governance assessment allows for a wide range of judgments to count as quality consent. The actual benefits delivered may outstrip or fall short of the perceived benefits, the perceived benefits, may be nonoverlapping, and there may be variable sophistication in terms of the understanding and how and why these benefits were achieved. ${ }^{21}$ The notion of a positive governance assessment allows for entirely idiosyncratic judgments about the goods government ought to serve, letting a "thousand flowers bloom."

\subsection{Non-Quality Consent}

However, not all governance assessments meet the conditions for quality consent. How is non-quality consent to be distinguished? I will approach this question through an examination of paradigmatic cases of non-quality consent. First, consent-to-rule which is brought about by

\footnotetext{
${ }^{21}$ While I cannot give a full account here of the judgment underlying quality consent, what is essential is that it involves a (perhaps implicit) belief that the political order is subjectively valuable.
} 
certain kinds of fear and intimidation does not count: it does not qualify as consent-to-rule as I have articulated it, which is the voluntary acceptance of a system of rule. ${ }^{22}$ There are three further cases of consenting subjects whose consent, at least intuitively, should not count in favor of legitimacy: the dominator, the underling, and the culpably ignorant. Any adequate definition of quality consent ought to exclude these cases:

a) The dominator is someone who consents to rule on the basis of a judgment that it is acceptable to deprive others of basic security.

b) The underling is someone who consents to rule on the basis of a judgment that it is acceptable for himself to be deprived of basic security.

c) The culpably ignorant is someone whose consent to rule is strongly insensitive to facts about whether some subjects are being deprived of basic security.

It seems intuitive that these three cases should not bear positively on assessments of legitimacy. Note that they are all partly characterized in terms of basic security, i.e. minimal order and protection from violence.

Why set the bar so low? A variation on the view that may be more attractive to some readers is to set the bar higher, such as protection of human rights, or provision of basic capabilities. This variation would still have the structure of an actual quality consent view. But in proposing the sovereignty conception, I aim to construct an account of legitimacy that is more agnostic about the relationship of legitimacy to other political values, such that it has a wider application than only to liberal democracies. If we were to examine instances of political orders in various historical periods - honor-based tribal communities, medieval feudal systems, fundamentalist theocracies, modern liberal democracies — we would find that virtually every

\footnotetext{
${ }^{22}$ Not all sources of fear are the same, and only some disqualify the consent as freely given (e.g. when a subject would not consent but for the intimidation brought to bear on her by her regime).
} 
system of political rule advances the claim that it (at least) provides for the basic security of those it addresses as its subjects. Though the regimes may fail to, or not even attempt to, actually provide for all subjects' basic security, the regimes nevertheless make this claim. Insofar as a regime claims to rule, it makes what I call the claim of minimally competent government (CMCG). All three of the paradigmatic cases of problematic consent rest on judgments that directly conflict with this claim.

Therefore, in light of the three paradigmatic cases, I construct the following filter for determining quality consent. In order for consent to contribute to legitimacy, it must be based on governance assessments that meet the following two necessary conditions:

I. The assessments do not explicitly contradict the claim of minimally competent government. That is, the governance assessments do not contain judgments that explicitly deny that each subject's basic security is to be provided for by the regime.

II. The assessments are weakly reliable regarding whether the claim of minimally competent government is being met. That is, the governance assessments exhibit some weak counterfactual sensitivity to governance outcomes, namely those facts about whether the regime is providing for all subjects' basic security.

These conditions suffice to exclude the dominator, the underling, and the culpably ignorant.

To make clearer the implications of my view, examples of quality consent would include: the consenting libertarian who thinks he is better off than he would be otherwise but cares little for distributive justice, the consenting egalitarian who thinks the least well off are better off than they otherwise would be, and the consenting religious believer who thinks governance adequately enables the welfare conditions for spiritual development of his co-religionists but cares little for outsiders. These cases qualify because their consent is based on the right sort of 
governance assessment, namely, the recognition of perceived benefits based on judgments that do not fall afoul of (I) and (II) above. A more ordinary case that also counts as quality consent is the simple-minded person who affirms something vague, such as, "Things around here are going well enough for the most part."

However, an example of non-quality consent is a consenting racial supremacist who believes his race ought to dominate others. He subjectively values rule that aims to compromise the basic security of some subjects. The principled reason for why his consent is disqualified is that the judgment on which it is based directly contradicts the government's claim to be minimally competent. Nevertheless, the sources of disqualification are more limited than in other theories; accordingly, being a libertarian or a religionist does not disqualify a citizen's consent. This admitted laxity in the 'quality filter' is designed to allow even minimal awareness of governance success to qualify the consent as relevant for legitimacy. This latitude is appropriate in order to balance out the fact that non-consent bears (negatively) on legitimacy whether or not it is warranted by the governance facts.

One implication of this approach is that legitimacy largely becomes a matter of what people believe about outcomes. Strictly speaking, there is no 'welfare outcomes floor' built into the theory, and deliberately so. However, while it's true that failures of governance (failure to fulfill $\mathrm{CMCG}$ ) do not directly reduce legitimacy, they tend to undermine it, because they make it much more difficult to achieve instances of quality consent among subjects.

\subsection{Achieving Actual Consent Among Subjects}

To summarize thus far: the sovereignty conception claims that regimes are legitimate 
insofar as they achieve actual quality consent to rule among subjects. ${ }^{23}$ Actual quality consent captures the complex idea that individual consent to rule is non-instrumentally valuable, but that its value is nevertheless dependent. Its value is dependent because consent to rule, in order to contribute to legitimacy, must be based on positive governance assessments. When it is, it is quality consent, and a regime is legitimate to the degree that its subjects exhibit quality consent. Two further features of the view now come into view: the proportional basis of legitimacy, and the role of aiming at consent.

On the sovereignty conception, legitimacy corresponds to the proportion of individuals who consent: the greater the proportion of free submission to 'rule' under the authority, the more legitimate is the rule. This proportional approach makes sense if we imagine the case of a 'legitimacy utopia,' a voluntary association of individuals whose activities are just and welfareenhancing. In this imaginary association, to the degree that its activities require the exercise of power and authority, each individual affirms his voluntary subjection to the governing order. The unanimous consent in a legitimacy utopia reflects our intuition that, in a perfect world, citizens' acceptance of rule reliably tracks whether the rule is just and welfare-enhancing. As we gradually move away from the utopian case, we may imagine that fewer subjects exhibit quality consent. The sovereignty conception claims that the fewer instances there are of quality consent, the less legitimate is the rule. ${ }^{24}$

In order to realize the ideal of voluntary rule, a regime must treat each subject's interest in voluntary rule as an interest worthy of being promoted and fulfilled for its own sake (rather than, for example, as a means to compliance). While the primary interest of a subject is in achieving

\footnotetext{
${ }^{23}$ Though I do not have space to discuss it here, the view presupposes an independent account of subjecthood, lest a regime seek to achieve legitimacy by manipulating who counts as a subject.

${ }^{24} \mathrm{An}$ upshot of this approach is that legitimacy assessments are scalar rather than binary. I argue elsewhere that a scalar concept has more theoretical advantages than costs.
} 
quality consent, there are secondary interests in having the opportunity or possibility of exhibiting quality consent and in being treated as someone for whom consent-to-rule is noninstrumentally valuable. Therefore a regime may aim at quality consent by advancing the secondary interests even if the primary interest is not achieved. When quality consent is aimed at and freely given, its achievement adds to the fulfillment of the ideal of voluntary rule.

\section{Advantages of the Sovereignty Conception}

In the remainder of the paper I compare the sovereignty conception to the other consentbased views in order to show its advantages. With respect to contractualism, the chief advantage of the sovereignty view is that it better handles the problem of involuntary rule. Consider two examples in which the personal sovereignty conception is more sensitive to the problem of involuntary rule: a decent hierarchy and a dictatorship of enlightened guardians.

Consider first a decent hierarchy. Imagine that a particular community contains a small linguistic/religious/cultural minority, wholly located on a political border shared with neighbors. This minority group is small and actively disliked by every political community in the region. By remaining a part of the original community, they believe (say, truly) that they are better off than in any alternative community, including if they were to secede. Although their basic security is provided for, they are not treated as full political equals -- say that they lack some substantive and some formal equal political rights. A contractualist account would typically deny legitimacy, as hypothetical agreement is premised on some presumption of recognition of political equality. This denial seems to tacitly assume that valid consent requires full equality. But, given that we do not require full equality for consent to be legitimating in other spheres such as commercial exchange and medical care (though we may impose other requirements), this assumption is 
questionable. Many people are not treated equally in their political orders, but they nevertheless consent to their regime on other permissible grounds.

The second example is rule by enlightened elites. ${ }^{25}$ Imagine a meritocracy in which those who rule are selected by past rulers on the basis of qualifications related to competence. Imagine they are permanently appointed and tend to enjoy a higher level of wellbeing because of their high social standing. Say that the society meets a very high standard of justice, which is that everyone is as well off as they could have possibly been, due to the rulers' wisdom and virtue. It seems that hypothetical consent ought to be imputed to everyone, since not only is everyone better off than some alternative scenarios, everyone is better off than all alternative scenarios. ${ }^{26}$ However, say that the people do not believe that powers of office are assigned for the general good, because the inequality in welfare tracks relative power, and this welfare-determining status is assigned non-transparently. And so, say that $95 \%$ of the subjects do not consent to rule, and a significant proportion actively seeks revolution. It seems that, while there may be some welfarebased or justice-based argument for the regime, the level of its legitimacy seems very low. This is because the rule is involuntary at the collective level and at the individual level. These two examples illustrate that the sovereignty conception fits our intuitions about voluntary rule better than the contractualist approach does.

This discussion highlights that the sovereignty view advances a kind of asymmetry between consent and non-consent. Since this may seem counterintuitive, I want to address why this feature is appropriate. For the contractualist, in the same way that certain cases of consent (the unreasonable ones) do not bear on legitimacy, certain cases of non-consent (the

\footnotetext{
${ }^{25}$ This stylized description arises from the example of the guardians in Plato's Republic, but it is also meant to encompass technocratic administration by civil servants in contemporary societies.

${ }^{26}$ One may object that welfare should be taken to include political equality and participatory rights, in which case everyone is not as well off as they could be. However, one could include these in the welfare definition and still
} 
unreasonable ones) do not bear on legitimacy. Contractualism thus subscribes to a kind of theoretical symmetry in the way consent and non-consent are 'counted.' In contrast, the sovereignty conception defends what may be deemed an "asymmetric" view. Legitimacy is reduced whenever non-consent occurs, whether or not it is reasonable or well-grounded. Legitimacy is reduced because all kinds of non-consent set back the interest in voluntary rule. So the charge of asymmetry is a misnomer, because the sovereignty view construes consent as a dependent good, one whose value depends on certain conditions being met. Since its value is conditional, it is fitting that non-consent and non-quality consent both fail to advance voluntary rule. ${ }^{27}$ This feature also allows the sovereignty view to avoid fixing the facts about consent in a way that embeds partisan presumptions, one of contractualism's shortcomings. ${ }^{28}$

\subsection{Comparison to Voluntarism}

The sovereignty view also has advantages relative to voluntarism, but they emerge on different axes of comparison than the ones pertaining to contractualism. The two dimensions I will particularly discuss are the quality filter and the emphasis on individualism.

The first advantage of the sovereignty conception over voluntarism pertains to the

generate the example, since even with more participatory government, it is still plausible that there be sufficient inequality of outcomes to foment rebellion.

${ }^{27}$ Claiming that non-consent and non-quality consent are similar in this respect does not imply that they are otherwise similar - indeed, they are very different in terms of their political consequences.

${ }^{28}$ Earlier I criticized contractualism for relying on idealized versions of consent, particularly ones that employed partisan assumptions about what are and are not relevant factors in political evaluation. It may seem that the quality filter also involves an idealization of consent, insofar as the judgments underlying it must square with CMCG. To this charge, I reply that there is one sense in which the sovereignty view clearly fares better than contractualism: it accepts without idealization the significance of instances of non-consent to rule, admitting that individual instances of non-consent always undermine legitimacy. Even if the individual's judgments are unjustified or grossly immoral, there is no tidying things up with ideal theory. Regarding how to classify instances of consent: the sovereignty conception's imposition of a quality filter does introduce some value judgments about consent's significance, but these are less problematic than contractualism in two ways. First, the amount of idealization is comparatively minor, because it is extremely accommodating of individuals' idiosyncratic views regarding the relevant factors in political evaluation. Second, the quality filter employed by the sovereignty conception does not draw on assumptions about a pre-political morality of justified coercion. For this reason, it can be used to argue for the legitimacy of non-liberal 
theoretical underpinnings of the quality filter. Earlier I noted that on the voluntarist view expounded by Simmons, there is a proviso on whether consent is valid, one that may seem similar in form to the quality filter: "We cannot bind ourselves by consent to immoral arrangements" $\{$ Simmons, 746$\}$. Imposing this proviso is well motivated but inadequately defended. First, the standard of "immoral arrangements" is obscure and highly contested. Such a standard entails that in order to apply the proviso in determining the facts about consent (that, in turn, fix the facts about legitimacy), we must first settle the necessary and sufficient conditions for a political arrangement to be moral. ${ }^{29}$ But it is often precisely when we face intractable moral disagreement that we most keenly need legitimacy standards. The second reason the proviso is not adequate to the purpose is structural: it presupposes and then relies upon an independent principle about the moral circumstances under which consent can authorize coercion. But the question under consideration is precisely how consent plays a role in legitimizing political rule, which in turn provides part of the justification for coercion. ${ }^{30}$ These are thorny questions that may not ever be perfectly resolved, but I will now show why the sovereignty conception addresses them more adequately.

Whereas voluntarism says that the threshold for consent to be legitimating is when the political arrangements are moral, the sovereignty view has a lower bar. Essentially, the consent is legitimating when it does not conflict with the claim of minimally competent government. The imposition of a quality filter in terms of a claim to provide for basic security is narrower and clearer than the vague "immoral arrangements" criterion. Moreover, rather than drawing on a

states, demonstrating that it is less partisan than other consent theories.

${ }^{29}$ There also will likely be a problem with determining when political arrangements are moral independent of their legitimacy, but Simmons does not address this.

${ }^{30}$ The presupposition is problematic because it forecloses part of the question under consideration. Whatever principle Simmons (or Locke) is appealing to in order to justify applying such a proviso must have the following form: Coercion in the presence of consent (including that done by regimes who claim to be legitimate) is justified only when an arrangement is moral. But such a principle forecloses debate about the very question under 
general principle of permissible coercion that claims to be objectively true, the sovereignty conception derives the quality filter from historical generalities about political orders. Its status as a valid quality filter arises from the trans-historical claim of minimally competent government, which is to provide for basic security. It takes as the minimum aim of all political orders to be providing for basic security, so it need not take a position about the ultimate aims of government, what counts as successful government, or even the necessary conditions for successful government. Therefore, in virtue of its source and its content, the quality filter on the sovereignty conception is less problematic that the voluntarist's proviso.

The second major dimension on which the sovereignty conception is superior to voluntarism is the emphasis on individualism. Both views subscribe to an ideal of voluntary rule that gives prime significance to the actual facts about whether individuals consent. But the sovereignty conception has much more to say about achieving voluntary rule among all subjects, considered collectively. In order to support this claim, I must first clarify several related points of contrast between the views.

The voluntarist approach employs an exclusively individualistic approach to assessing legitimacy, since legitimacy can be determined for each individual independent of other subjects' relationship to the regime. The sovereignty conception, instead, construes legitimacy as a feature of a regime with respect to its subjects collectively. To whatever degree a regime is legitimate, its legitimacy applies equally to all the subjects, whether or not each has consented in her individual case. Therefore, the sovereignty conception avoids the problems of assigning legitimacy assessments subject-by-subject. Accordingly, it is better placed than voluntarism to deny that unanimous consent is necessary for legitimacy. However, it nevertheless shares voluntarism's concern for the individual, as evidenced by tying legitimacy to actual instances of non-consent. 
However, one may be reluctant to give up the exclusively individualistic approach when considering a scenario in which some individuals or groups are consistently treated much worse than others. For example, Thomas Shelby has argued that citizens who are differentially liable to be the victims of violent crime have correspondingly different political obligations (Shelby 2007). But the differentially worse outcomes for some individuals ought not just affect the legitimacy of the regime for those individuals, while permitting the legitimacy of the regime for other individuals to be unaffected. Indeed, as this example suggests, the notion of political obligation is better suited to be the dimension on which individual differences may vary according to differentially worse treatment. By construing legitimacy at the collective rather than individual level, and by distinguishing legitimacy from political obligation, the sovereignty view is able to accommodate this important consideration.

Ultimately, the sovereignty view handles the tension between the individual and collective in a way that is more subtle and illuminating than either contractualism or voluntarism. This is because it eschews unanimity without embracing exclusive individualism. Rather, it makes room in the account of legitimacy for the primacy of individual consent, while maintaining that such consent issues in legitimacy only in combination with other subjects' consent. It is a strength of the sovereignty conception that it neither collapses collective and individual instantiations of voluntary rule, nor does it hold that they are entirely independent.

\subsection{The Value of Legitimacy}

Recall that one aim at the outset was to identify a consent-based theory of legitimacy that showed why it was a concept distinct from other political concepts and at the same time something we should value. I will now discuss the sovereignty view in light of these desiderata. 
Whether the sovereignty conception of legitimacy can illuminate what is uniquely valuable about legitimacy depends in part on what counts as quality consent. If the quality filter is too demanding, then the value of legitimacy can't be adequately distinguished from the values of liberalism, democracy, etc. On the other hand, if the quality filter is relatively undemanding, then it's hard to see why quality consent is worth achieving. When the quality filter rests on claims of objective morality, as it does for the voluntarist, then one may straightforwardly argue for the significance of legitimacy on that basis. But since the sovereignty conception does not avail itself of such a claim, the question becomes: how far can the view move away from relying on claims of objective morality and still assert that quality consent is something we should value $?^{31}$ Fairly far, I hope to show, and to do so I will to return to the characterization of voluntary rule.

The good that is instantiated by voluntary rule can be construed as a sort of congruence, or alignment, between the facts about organized power and the attitudes of those subject to that power. When voluntary rule is achieved, there is at least some partial alignment between what an individual values and what goods are promoted by the political order to which he is subject (though it may also promote other goods, ones valued by other subjects). In fact, the congruence involves three levels:

(i) the regime claims to benefit its subjects through the exercise of power;

(ii) the regime benefits its subjects through the exercise of power; and

(iii) an individual (or group) believes that the regime benefits subjects through the exercise of power.

When these three statements can be made together, the situation represents a sort of unforced

\footnotetext{
${ }^{31}$ This question applies in general to theorists in the political realism vein, who take political moralism to be the only alternative (Williams 2007). Elsewhere I argue that the view defended here avoids shortcomings of both
} 
alignment or congruence between a regime's governance and the attitudes towards that governance among subjects.

The instantiation of a voluntary ruling relationship at the level of a group of subjects represents, I propose, a kind of excellence exhibited by the regime in question. Therefore, voluntary rule has value at the impersonal level of subjects considered as a group, as well as at the personal level of each individual. If the good realized by voluntary rule can be characterized by a kind of unforced alignment or congruence, then the absence of voluntary rule may be characterized as a kind of alienation or dissonance. This alienation from one's own social or political order arises because one cannot authentically affirm the regime to which one is subject as in any sense worthwhile, i.e. as providing at least some benefits that one values subjectively. The absence of voluntary rule - involuntary subjection - also instantiates a kind of disvalue, for an individual and for a political community.

How does the value of attaining voluntary rule compare to other political values? The sovereignty conception recognizes that our interest in voluntary rule is one interest among others at stake in being ruled. Accordingly, it allows that other things matter besides legitimacy for political justification. It does not commit to the lexical priority of legitimacy over other political values. The view does not entail that achieving voluntary rule is a necessary condition for all else to be valuable to an individual, or that it is a necessary condition for a regime to rule permissibly. Indeed, a loss on the dimension of legitimacy is sometimes desirable for the sake of other values. $^{32}$

Having shown how the sovereignty conception is oriented towards the valuable ideal of

\footnotetext{
realism and moralism.

${ }^{32}$ The reader may wonder: what is the upshot of legitimacy? In my view, legitimacy does not directly entail answers to questions about authority, obligation, right of revolution, etc., but it does bear on these questions. The conception of legitimacy proposed here is meant to be compatible with a variety of accounts of authority and
} 
voluntary rule, nevertheless there remain two kinds of subjects who may complain that their interest in voluntary rule is not given due consideration: the person who does not consent, and the person whose consent is non-quality consent. I will briefly sketch how a reply to these two kinds of subjects would proceed.

First, consider the subject who does not consent. If the value of voluntary rule is in overcoming alienation in order to bring about congruence and identification between a subject and his regime, then why should a non-consenting subject feel that his interest in voluntary rule has been adequately respected? In other words, why is a regime legitimate even for the nonconsenters? Whereas other views claim that consent of the individual is appropriately valued only when it is actually obtained, the sovereignty conception claims that there is a way of valuing and showing concern for consent that doesn't require that it be obtained.

According to this characterization, a regime may relate appropriately to a subject's interest in voluntary rule in two possible modes. One is for the regime to actually realize voluntary rule for that individual by providing benefits that result in a positive governance assessment. Failing this, the other mode is for the regime to respect, in a non-instrumental way, their interest in voluntary rule. While respecting the interest is second-best to realizing it, it is still important. Consider what the absence of this respect would involve: a regime's treating the interest in voluntary rule in the wrong way, i.e. Valuing consent only as a means, or not valuing consent at all. Valuing consent non-instrumentally, even when consent is not obtained, counts as a form of respect for the interest in voluntary rule.

Another part of the reply is that a particular subject's interest in voluntary rule is respected when the rulers aim to achieve the consent of all the subjects. In my view, this position is analogous to consequentialism with respect to individual utility. When a decision is made on 
behalf of a group with a consequentialist justification, then just because an individual's utility is not advanced by that particular decision does not mean that their utility does not count, or count the same as everyone else's. Likewise, just because an individual's consent is not achieved, that does not mean that his consent does not count, or count the same as everyone else's. This kind of argument is distinct from arguing that it is the possibility or the capacity for consent which matters. ${ }^{33}$ The capacity to consent is not its own end; rather, the capacity is to be understood in light of the value of achieving voluntary rule, for which it is an enabling condition. Therefore, aiming at consent in a non-instrumental way is necessarily involved in realizing the value of voluntary rule. Obviously much more needs to be said, but the response would proceed along these lines.

Now consider the subject whose consent is non-quality. ${ }^{34}$ In claiming that involuntary subjecthood is bad, it is not yet clear why voluntary subjecthood is good only in combination with some judgments. ${ }^{35}$ Earlier I described "the dominator" and "the underling" as subjects whose judgments about rule explicitly deny that a regime ought to, at a minimum, aim at providing for the basic security of all subjects. On may ask, why exactly isn't their interest in voluntary rule being advanced? They presumably identify with the regime and feel at home within it, but they affirmatively deny that the government ought to be fulfilling CMCG.

\footnotetext{
${ }^{33}$ It fundamentally differs, therefore, from Scanlon's treatise about the significance of choice. See (Scanlon 1988).

${ }^{34}$ One may be skeptical that anything short of quality consent is really consent to rule, in a sense worth caring about. Indeed, some theorists claim that consent to a dominating regime is not really consent to rule but consent to a system of mastery, thus violating the very ideal of voluntary rule. But this stance would render it logically impossible to consent to a dominating or unjust political order. A theory of legitimacy ought not deny that people consent to the exercise of power and authority under immoral conditions and for immoral reasons (whether consciously or not). The sovereignty conception allows that people may consent to dominating regimes (e.g. South African apartheid), and this consent counts as genuine consent, though it may fail to be quality consent. When other theorists deny that this counts as consent, they are really denying that the consent has a certain sort of status (that it is legitimizing in some way). But this comes to the same thing that a quality filter comes to, except that the sovereignty conception does not claim as a matter of logic that people can't consent to rule that is unworthy of consent. There is a difference between a regime that has consent and a regime that is worthy of consent. Neither of these can be conceptually reduced to the other, and they are both relevant to an individual's interests.

${ }^{35}$ The exclusion of some cases will require justification wherever there is a quality filter, but the explanation will
} 
According to the sovereignty view, a subject's interest in voluntary rule is not advanced when the judgment on which his consent-to-rule is based conflicts with the claim of minimally competent government (CMCG). ${ }^{36}$ According to the above arguments about the enabling role of aiming at consent, voluntary rule at the group level can only be realized when a regime treats each subject's interest in voluntary rule as non-instrumentally valuable. ${ }^{37}$ If some subjects explicitly deny this, then they undermine the regime's aiming at group voluntary rule. The reason they undermine the regime's aim is because their consent is based on treating other subjects' consent as either not valuable or only instrumentally valuable. For example, the judgment on which the dominator's consent is based explicitly denies the non-instrumental value of voluntary rule for some subjects. It then becomes virtually impossible for the regime to aim at the dominator's consent while also aiming at other subjects' consent non-instrumentally. Therefore, those who consent to rule on grounds that conflict with the CMCG set back one of the enabling conditions for realizing the value of voluntary rule, and so they set back the interest in voluntary rule. Again, much more would need to be said, but the response would proceed along these lines.

\section{Conclusion}

I have argued that there are considerable shortcomings in the two dominant approaches to consent-based theories of legitimacy, contractualism and voluntarism. Although these consent-

\footnotetext{
obviously vary according to the filter.

${ }^{36}$ Alternatively, one might claim that the interest in voluntary rule is advanced only by consent to political orders that actually achieve their minimal claim, that is, provide for basic security for everyone. I do not take this route because it would require either stipulating that "achieving CMCG" is a constitutive ingredient in rule, or stipulating that it is a constitutive ingredient in the voluntarism involved in voluntary rule. The former is plainly false, and the latter has more theoretical costs than benefits, in my view.

${ }^{37}$ One potential problem with this response is that it seems to only require a concern for enough subjects consenting to rule, rather than a concern for all subjects consenting to rule. But perhaps this is not such a bad problem, since the changeability of people's attitudes requires an ongoing practical concern for the consent of all (in losing the consent of some, you may need to win some others). So a concern to achieve enough consent could translate in practice to a concern for the consent of all.
} 
based theories affirm the ideal of voluntary rule, they lack appropriate sensitivity to factors that should matter for voluntary rule - namely, the actual levels of consent and non-consent among the subjects of a regime. In order to show that these shortcomings can be avoided, I have defended a different interpretation of the interest in voluntary rule as the basis of legitimacy. The sovereignty conception bases legitimacy on the proportion of actual consent among subjects in a regime, where each individual's consent is based on her own positive governance assessment. In articulating the sovereignty conception, I proposed a notion of quality consent to rule arising from the claim of minimally competent government. Finally, I argued that the notion of quality consent affords a theory of legitimacy that shows why legitimacy is valuable without relying on liberal democratic presumptions. Thus the sovereignty conception, as I have begun to defend it here, represents a promising alternative to other consent-based theories of political legitimacy. 


\section{$\underline{\text { References }}$}

Ashford, Elizabeth, and Tim Mulgan. 2012. "Contractualism." In The Stanford Encyclopedia of Philosophy, edited by Edward N. Zalta, Fall 2012. http://plato.stanford.edu/archives/fall2012/entries/contractualism/.

Buchanan, Allen. 2013. The Heart of Human Rights. Oxford University Press.

Buchanan, Allen, and Robert O Keohane. 2006. "The Legitimacy of Global Governance Institutions." Ethics \& International Affairs 20 (4): 405-37. doi:10.1111/j.17477093.2006.00043.x.

Cohen, Joshua. 1996. "Procedure and Substance in Deliberative Democracy." In Democracy and Difference: Contesting the Boundaries of the Political, edited by Seyla Benhabib. Princeton, N.J: Princeton University Press.

Copp, David. 1999. “The Idea of a Legitimate State.” Philosophy \& Public Affairs 28 (1): 3-45. doi:10.1111/j.1088-4963.1999.00003.x.

Estlund, David. 2007. Democratic Authority: A Philosophical Framework. Princeton University Press.

Horton, John. 2012. "Political Legitimacy, Justice and Consent." Critical Review of International Social and Political Philosophy 15 (2): 129-48. doi:10.1080/13698230.2012.651015.

Huemer, Michael. 2012. The Problem of Political Authority: An Examination of the Right to Coerce and the Duty to Obey. Palgrave Macmillan.

Nozick, Robert. 1974. Anarchy, State, and Utopia. Basic Books.

Pettit, Philip. 2012. On the People's Terms: A Republican Theory and Model of Democracy. Cambridge University Press.

Rawls, John. 2001. Justice as Fairness: A Restatement. Edited by Erin Kelly. Cambridge, MA: Harvard University Belknap Press.

Raz, Joseph. 1988. "Facing Up: A Reply." S. Cal. L. Rev. 62: 1153.

Rousseau, Jean-Jacques. 1987. Basic Political Writings. Hackett.

Sandbu, Martin E. 2007. "Valuing Processes." Economics and Philosophy 23 (02): 205-35. doi:10.1017/S026626710700137X.

Scanlon, Thomas M. 1988. "The Significance of Choice.” The Tanner Lectures on Human Values 8: 149-216.

Sen, Amartya. 1997. "Maximization and the Act of Choice." Econometrica 65 (4): 745-79. doi: $10.2307 / 2171939$.

Shelby, Tommie. 2007. “Justice, Deviance, and the Dark Ghetto." Philosophy \& Public Affairs 35 (2): $126-60$.

Simmons, A. John. 1999. “Justification and Legitimacy.” Ethics 109 (4): 739-71.

Weber, Max. 1978. Economy and Society: An Outline of Interpretive Sociology. University of California Press.

Williams, Bernard. 2007. In the Beginning Was the Deed: Realism and Moralism in Political Argument. Princeton University Press. 